\title{
Report
}

\section{Treatment of Spinal Deformities - The Appearance of a Conflict of Interest}

\author{
Hans Rudolf Weiss \\ Schroth Best Practice Academy, Abtweiler, Germany \\ Email address: \\ hr.weiss@koob-skoliose.com
}

To cite this article:

Hans Rudolf Weiss. Treatment of Spinal Deformities - The Appearance of a Conflict of Interest. International Journal of Health Economics and Policy. Vol. 5, No. 1, 2020, pp. 9-14. doi: 10.11648/j.hep.20200501.12

Received: April 11, 2020; Accepted: April 24, 2020; Published: May 28, 2020

\begin{abstract}
The majority of patients with spinal deformities need some type of treatment. Typically, physiotherapy and bracing are sufficient and a minority of cases require surgical treatment. However, in many international papers on spinal deformities surgical issues are investigated while conservative management of spinal deformities is definitively underrepresented. The purpose of this survey is to look more deeply into the implications of the surgical societies and spine surgeons lobbyism on the payroll of industry and how these groups influence payments (reimbursement) made by national health services or health insurance systems worldwide for the treatments of patients with spinal deformities. Materials and methods: An international network of specialists for the conservative treatment of spinal deformities have performed a survey analyzing the cost of spinal surgery for spinal deformities (scoliosis), the cost of a brace and whether insurance/the NHS reimbursement applies with surgery or bracing. Results: In most countries surgery is paid without co-payments by the patient. In Japan, China and Ukraine co-payments are necessary for surgery. There are more restrictions when looking at payments for braces. In some countries, braces are not covered by the health care systems or insurance companies at all (China, Indonesia) in others the amount covered is only minimal (Turkey, Ukraine). Conclusions: Evidence in scientific literature is not reflected in the political decision making in parliaments. Evidence based treatment approaches for patients with spinal deformities are not necessarily reimbursed by local health care systems while surgery without scientific evidence is reimbursed more easily although it is more expensive. The most economic approach would be to pay for high quality conservative treatment in order to largely prevent the need for surgery. Surgical indications should be approved by an independent non-surgical specialist for spinal deformites.
\end{abstract}

Keywords: Spinal Deformities, Treatment, Surgery, Orthotics, Cost of Treatment

\section{Introduction}

The majority of patients with spinal deformities will not need spinal surgery [1-4]. Today we know that $2-4 \%$ of the population have some sort of scoliosis, however only $0.5 \%$ of the population will need some kind of treatment [1-4]. When compared to patients with scoliosis, patients with kyphosis have a better prognosis $[5,6]$. The majority of all scoliosis cases are patients with adolescent idiopathic scoliosis (AIS) comprising $80-90 \%$ of all scoliosis cases. These patients with AIS are otherwise healthy and even when staying untreated they will not suffer from severe health problems [1-4]. The majority of patients with a kyphosis have Scheuermann's kyphosis, a deformity also not leading to severe health issues. Therefore, for most of the patients requiring treatment, physiotherapy and bracing will be sufficient and only the minority of the cases would need surgical treatment $[5,6]$.

However, in most of the papers (international literature) on spinal deformities surgical issues are investigated [7-9], while conservative management of spinal deformities is definitively underrepresented.

The international specialist societies of spine surgeons are well networked and increasingly influence guidelines, FDA approval of devices and politics [10]. This problem has already been addressed by Prof. Martha Hawes, a scientist who described the conflict of interests of spine surgeons in her book entitled 'Scoliosis and the Human Spine [11].'

While conservative management of patients with spinal 
deformities (physical rehabilitation and brace treatment) is supported by high quality evidence still today there is no evidence for a beneficial long-term effect of spinal fusion surgery [7-9, 12-16]. Nonetheless, the use of conservative measures is constantly being questioned, while the operative treatment of spinal deformities continues to be used largely without self-criticism and paid for by the community of solidarity or by the patients themselves. The editorial board of the specialist journals, published by the specialist societies, mainly contains spinal surgeons, who are often critical of effective conservative treatments [10]. It is therefore not surprising that the hurdles for the publication of effective conservative treatment strategies in these journals are sometimes higher than for the publication of surgical measures.

The conflict of interest of spine surgeons on the industry payrolls is not well reflected in the scientific literature. However, there are a number of publications shedding some light on this issue [10,17-21], which is summarized in a testimonial by Dr. Charles D Rosen [10].

The purpose of this survey is to look more deeply into the implications of the lobbyism of the surgical societies and spine surgeons on the payroll of industry and how these groups influence payments made by national health services or health insurance systems worldwide for the treatments of patients with spinal deformities.

\section{Materials and Methods}

Within our international network of specialists for the conservative treatment of spinal deformities we have performed a survey containing the following queries:

1. Country:
2. Cost of spinal surgery for spinal deformities (scoliosis):

3. Cost of a brace:

4. Is surgery reimbursed by the insurance / NHS (yes / no):

5. Is a brace reimbursed by the insurance / NHS (yes / no):

6. In case 4=yes; are all kinds of surgery reimbursed (yes / no):

7. In case 5=yes; are all kinds of braces reimbursed (yes / no):

\section{Results}

Some of the participants only provided the answers to the questions, others added some background information. The results of this survey are summarized in Table 1.

In most of the countries surgery is paid without co-payments by the patient. In Japan, China and Ukraine co-payments are necessary for surgery. It is apparent that more restrictions apply when analyzing the payments for braces. In some countries braces are not covered by the health systems or insurance companies (China, Indonesia) and in others the amount covered is only a small amount (Turkey, Ukraine).

In some countries, only certain types of braces prescribed by the surgeons are reimbursed by the insurance companies (Canada, Denmark, Japan, UK). In Denmark only Boston braces and the Providence nighttime brace are covered while Chêneau style braces are not, although the first end-result study on Chêneau braces had been published as early as 1985 . Also, it should be noted that this type of brace has been used in many countries of central Europe for many decades. In Germany, every brace prescription for patients in the statutory health insurance is approved by the medical service of the insurance company, but the surgical indication is not.

Table 1. Costs for the treatment of spinal deformities in different countries and payment by national health services / insurance companies.

\begin{tabular}{|c|c|c|c|c|}
\hline Country & Cost of surgery & Cost of brace & Surgery covered & Brace coverd \\
\hline China $(€)$ & 27,000 & $400-2.700$ & yes* & no \\
\hline Denmark $(€)$ & 67,000 & 4,000 & yes & yes \\
\hline Germany $(€)$ & $15.000-50.000^{\S}$ & $2.200-3.000$ & yes & yes \\
\hline Hong Kong $(€)$ & $30.000-50.000$ & $1.200-1.500$ & yes & yes \\
\hline $\operatorname{Japan}(€)$ & 50,000 & 1,500 & yes* & yes* \\
\hline Turkey $(€)$ & $5.000-40.000$ & $170-700$ & yes & $50,-€$ only \\
\hline Ukraine $(€)$ & 10,000 & 250 & yes* & yes* \\
\hline Indonesia (\$) & $10.000-30.000$ & $500-1.000$ & yes & no \\
\hline USA (\$) & $>100.000$ & $4.000-5.000$ & yes & yes* \\
\hline UK (GBP) & 35,000 & 2,700 & yes & (yes) \\
\hline
\end{tabular}

*=Co-payment by the patient necessary.

(yes)=not paid for by all insurance companies.

$\S=$ indirect sources, health services do not disclose.

\section{Discussion}

The surgical treatment of patients with spinal deformities is only indicated in very few cases, according to the relevant scientific reviews [7-9, 12-16]. There is no evidence that surgical treatment can improve the health of those affected in the long term [7-9, 12-16]. But even if one assumes the previously used threshold for the surgical treatment of an idiopathic scoliosis with a curvature of $40-50^{\circ}$, only a minority of those affected would need an operation. This means that the majority of cases with scoliosis and kyphosis would warrant conservative management with physical rehabilitation and brace treatment [5, 6, 22-26].

However, when it comes to monetary reimbursement of treatment, even in emerging countries like China and Indonesia it is easier to receive payment for surgery than for 
conservative treatment including brace treatment, which is regarded as being evidence based.

In other countries like Denmark or Netherlands only the braces are being paid for by the health services, which are prescribed by spine surgeons. Although today there is evidence that Chêneau style braces have better outcomes than the Boston brace or the Providence Brace, only the latter braces are approved by spine surgeons in Denmark and other Scandinavian countries.

Dr. Charles D Rosen [10] has pointed out that 'companies often pay large sums of money, sometimes in the millions, to high profile spine surgeons who can write favorable papers about their products under the guise of unbiased research.'

Many such surgeons are also in governance positions of the professional societies and on the editorial boards of journals. This allows them to influence the choice of presentations in society meetings, choice of educational workshops, as well as papers chosen for publication. Sometimes company stock is used by smaller companies to incent surgeons to promote their product, giving them a bias for surgical results to appear favorable [10].

Surgeon shareholders will form companies to manufacture or purchase their own devices at a fraction of the retail price of the major companies. All agree to implant only these devices then share in the subsequent profits [10].

Disclosing this information led to harsh consequences for Dr. Rosen: He was defamed, threatened by litigation, and behind the scenes surgeons on the payroll of industry tried to remove him from his post as a university professor at a well-known university clinic.

It is interesting to see that it is not necessary to have a patent to receive money from the device industry. Some surgeons only need some ,good ideas' in order to double their income with the help of the device industry. This also may lead to an increase of the amount of materials implanted by the surgeon. When we consider that one pedicle screw (Figure 1) costs more than $\$ 1,000.00$ [10], the turnover of the industry can unnecessarily be increased by the amount of screws implanted.

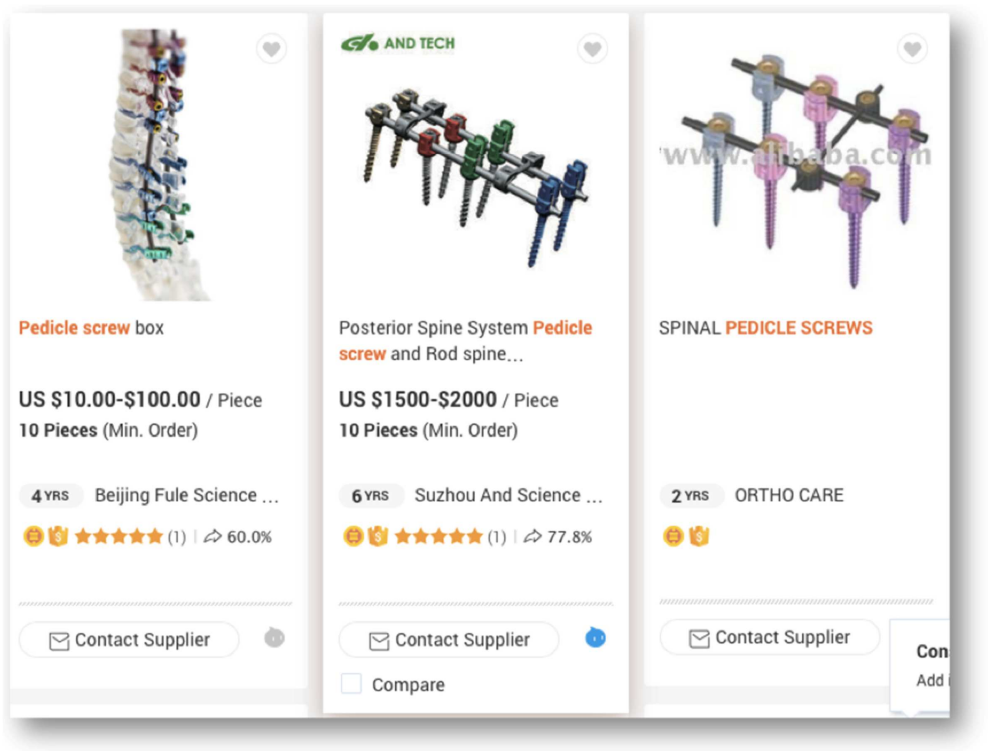

Figure 1. Pedicle screws as offered by Alibaba.com (https://www.alibaba.com/showroom/pedicle-screws.html)

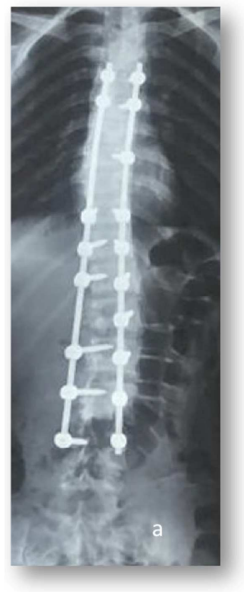

Figure 2. Screw saving operation made in https://www.facebook.com/groups/FranceScolioses/).
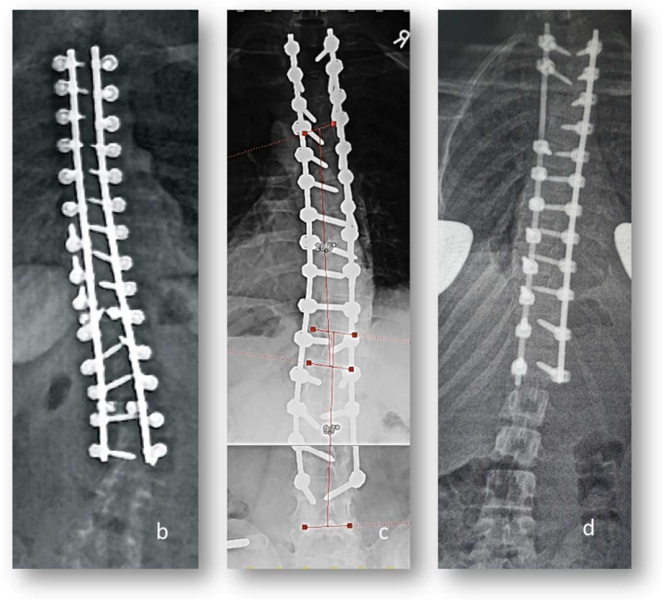

China

(a) and screw wasting

operations (b - $d ; \quad b$ from Facebook: 
Indeed, it is not necessary to place a screw at every possible space. However, as of today one finds more and more operations with all possible spaces occupied by a screw (Figure 2). Considering that every screw has a $25 \%$ chance of misplacement $[7,27,28]$ this behaviour unnecessarily increases the risk of the patient drastically!

About one-third of spine surgeons have an affiliation to one or more companies of industry [10]. Unfortunately, it is not required for these spine surgeons to disclose the amount they receive in full. Nevertheless, for an impression one can see the disclosures of the attendees and board members of the SRS meetings held every year [29].

Obviously, there are not only industry-sponsored surgeons on the FDA panel and other key spots [10], some obviously are also gatekeepers within the Cochrane collaboration. Usually, the Cochrane reviews from the former Cochrane Back Group have been published twice, once in the Cochrane library and secondly in the well reknown journal Spine as well.

The Cochrane review investigating the effect of spinal surgery in patients with adolescent idiopathic scoliosis (AIS) was without any evidence that the procedure investigated would improve the lives of the patients [13]. Therefore, the authors drew the conclusion that there is no evidence for surgery. The consequences would have been to conclude that there is no indication for surgery in patients with AIS. However, the authors were not allowed to draw any conclusion, but had to write: ,No conclusions can be drawn.' It was decided that Cochrane reviews without any conclusion would not be published in Spine as well.

When looking at the quality of publications in highly valued spine journals papers supporting surgery appear to be accepted too easily. We would like to present two examples:

The paper entitled,Scoliosis associated with Prader-Willi syndrome' is the presentation of a case report of a Prader-Willi patient having had spinal fusion successfully [30]. As Prader-Willi syndrome does not lead to tricky / complicated curvatures, hardly to correct this paper would not reveal any news and we would expect that a spine surgeon would be able to correct a scoliosis in the x-ray. The only difference to adolescent scoliosis patients is that Prader-Willi patients have more risk when undergoing surgery. So what value does the publication of this case report have?

Additionally, when someone would present a case report that a Prader-Willi patient had been treated effectively by conservative treatment would the same journal publish the results as easily?

The paper entitled, Results of Operative Treatment of Idiopathic Scoliosis in Adults' gives us the following conclusions: (Operatively) treated patients reported a significantly greater decrease in pain and fatigue and significantly more improvement in selfimage and in the ability to perform physical, functional, and positional tasks than did the untreated patients [31]. It was a retrospective chart review with $74 \%$ of the patients treated operatively returned for follow-up while in the non-operative group only $60 \%$ of the patients returned for follow-up. When doing a worst case analysis and analyse the patients lost to follow-up we would possibly find the opposite results: When we assume that patients lost to follow-up in the surgical group had the worse results of their treatment which is reasonable to assume [32] and the patients in the non operative group did not return to the surgeon because they were doing well, we might find the opposite results. So in conclusion this is a weak study in favour of surgical treatment published in a journal with high hurdles for submissions for being published.

These are only two examples for the bias that exists in orthopedic journals in favour of surgery.

The overuse of medical devices is well described on the website of the Association of Medical Ethics (http://www.ethicaldoctor.org/medical-ethics/articles/physicia n-payments-sunshine-act/who-is-reporting-payments-to-phys icians/). This overuse is supported by surgeons on the payroll of industry, serving as gatekeepers on journal boards, on the FDA board and also with influence on the decisions of the Cochrane collaboration [10]. These industry paid surgeons also act as advisors of politicians within the health care systems of countries all over the world. This industry driven lobby may also have led to the decision of health care politicians to pay for surgical treatment in many countries and to restrict payment for conservative treatment at the same time. This behaviour is in contrast with the evidence we have today. Conservative treatment of spinal deformities is based on evidence while surgical treatment is not [5, 6, 12-16, 22-26].

Economically this policy leads to more expenses for the society. While low cost and low quality conservative treatment will not necessarily reduce the amount of patients to be treated operatively, high quality conservative treatment may. In a recent review it has been shown that the success rate of brace treatment differs widely $(50-90 \%)$ [33]. If one calculates three high quality braces (success rate 90\%) to be made for a patient during the pubertal growth spurt the expenses for the health services will drop drastically because surgery then will only be needed in the vast minority of the cases. On the other hand, with all the long-term unknowns, the consequences of surgery might also be revision surgery, which may be more expensive than the initial surgery $[7,9,11,27$, 28]. In one study it has been shown that $48 \%$ of the patients treated needed a revision surgery within $5-20$ years [34]. Therefore, we cannot assume that with one payment for surgery the case is closed and we can anticipate more expenses to arise after surgery in the long-term.

\section{Conclusions}

Evidence in scientific literature is not reflected in the political decision making in parliaments. Evidence based treatment approaches for patients with spinal deformities are not necessarily paid for by local health care systems while surgery without scientific evidence is paid more easily although it is more expensive. The most economic approach would be to pay for high quality conservative treatment in order to largely 
prevent the need for surgery. Surgical indications in patients with spinal deformities should be approved by an independent non-surgical specialist for spinal deformites.

\section{Acknowledgements}

The author currently serves as the senior consultant for Koob GmbH \& Co KG. The company is held by the spouse of the author. He has held a patent on a sagittal realignment brace (EP 1604624 A1). The author is thankful to Dr. Marc Moramarco for copyediting this paper.

\section{References}

[1] Lonstein JE. Idiopathic Scoliosis. In: Lonstein J, Bradford D, Winter R, Ogilvie J (editors). Moe's textbook of scoliosis and other spinal deformities. Philidelphia: WB Saunders 1995, pp. 219-256.

[2] Goldberg CJ, Moore DP, Fogarty EE, Dowling FE. Adolescent idiopathic scoliosis: Natural history and prognosis. Stud Health Technol Inform 2002; 91: 59-63.

[3] Asher MA, Burton DC. Adolescent idiopathic scoliosis: Natural history and long term treatment effects. Scoliosis 2006; $1(1): 2$.

[4] Kuru Colak T. Natural History of Spınal Deformities. In: Moramarco M, Borysov M, Ng SY, Weiss HR (Edts.). Schroth's Textbook of Scoliosis and other Spinal Deformities, Cambridge Scholars Publishing, Newcastle upon Tyne, 2020, pp 159-184.

[5] Weiss HR, Turnbull D, Bohr S. Brace treatment for patients with Scheuermann's disease-a review of the literature and first experiences with a new brace design. Rewiev. Scoliosis 2009, 4: 22.

[6] Turnbull D, Weiss HR. Juvenile Kyphosis. In: Moramarco M, Borysov M, Ng SY, Weiss HR (Edts.). Schroth's Textbook of Scoliosis and other Spinal Deformities, Cambridge Scholars Publishing, Newcastle upon Tyne, 2020, pp 438-459.

[7] Hawes M. Impact of spine surgery on signs and symptoms of spinal deformity. Pediatr Rehabil 2006; 9 (4): 318-39.

[8] Weiss HR. Adolescent idiopathic scoliosis (AIS)-An indication for surgery? A systematic review of the literature. Disabil Rehabil 2008; 30 (10): 799-807.

[9] Moramarco K. Least potential harm with treatment for adolescent idiopathic scoliosis patients. Hard Tissue 2013; 2 (5): 44. [http://www.oapublishinglondon.com/article/1011].

[10] Rosen CD. Written Testimony of Dr. Charles D. Rosen President of the Association for Ethics in Spine Surgery. https://www.aging.senate.gov/imo/media/doc/hr188cr.pdf. Accessed April 9th. 2020.

[11] Hawes MC. Scoliosis and the Human Spine. West Press, Tucson Arizona, USA 2002, pp 107-109.

[12] Weiss HR, Goodall D. (2008) The treatment of adolescent idiopathic scoliosis (AIS) according to present evidence. A systematic review. Eur J Phys Rehabil Med 2008; 44: 177-193.

[13] Bettany-Saltikov J, Weiss HR, Chockalingam N, et al. Surgical versus non-surgical interventions in people with adolescent idiopathic scoliosis. Cochrane Database Syst Rev 2015; 4 (4): CD010663.

[14] Cheuk DK, Wong V, Wraige E, Baxter P, Cole A. Surgery for scoliosis in duchenne muscular dystrophy. Cochrane Database Syst Rev 2015; 10 (10): CD005375.

[15] Bettany-Saltikov J, Weiss HR, Chockalingam N, Kandasamy G, Arnell T. A comparison of patient-reported outcome measures following different treatment approaches for adolescents with severe idiopathic scoliosis: A systematic review. Asian Spine J 2016; 10 (6): 1170-94.

[16] Ward WT, Friel NA, Kenkre TS, Brooks MM, Londino JA, Roach JW. SRS-22r scores in non-operated adolescent idiopathic scoliosis patients with curves greater than forty degrees. Spine (Phila Pa 1976) 2017; 42 (16): 1233-40.

[17] Pollack A. Medtronic to Pay $\$ 1.35$ Billion to Inventor. https://www.nytimes.com/2005/04/23/business/medtronic-to-p ay-135-billion-to-inventor.html. Accessed April 9th. 2020.

[18] Feder BJ. Spinal Disk Closer to Losing Medicare Aid. https://www.nytimes.com/2006/03/18/business/spinal-disk-clo ser-to-losing-medicare-aid.html. Accessed April 9th. 2020.

[19] Abelson R. The Spine as Profit Center. https://www.nytimes.com/2006/12/30/business/30spine.html? pagewanted $=1 \&$ ei $=5070 \&$ en $=736 f 736 \mathrm{c} 5 \mathrm{e} 853 \mathrm{a} 2 \mathrm{f} \& \mathrm{ex}=117756$ 0000. Accessed April 9th. 2020.

[20] Oxford University Press's. Is There An Ethical Crisis in Spinal Surgery? https://blog.oup.com/2007/01/is_there_an_eth/. Accessed April 9th. 2020.

[21] Carreyrou J, McGinty T. Top Spine Surgeons Reap Royalties, Medicare Bounty. Wall Street Journal. https://www.wsj.com/articles/SB10001424052748703395204 576024023361023138. Accessed April 9th. 2020.

[22] Kuru T, Yeldan I, Dereli EE, Ozdincler AR, Dikici F, Colak I. The efficacy of three-dimensional Schroth exercises in adolescent idiopathic scoliosis: A randomised controlled clinical trial. Clin Rehabil 2016; 30 (2): 181-90.

[23] Monticone M, Ambrosini E, Cazzaniga D, Rocca B, Ferrante S. Active self-correction and task-oriented exercises reduce spinal deformity and improve quality of life in subjects with mild adolescent idiopathic scoliosis. Results of a randomised controlled trial. Eur Spine J 2014; 23 (6): 1204-14.

[24] Nachemson AL, Peterson LE. Effectiveness of treatment with a brace in girls who have adolescent idiopathic scoliosis. A prospective, controlled study based on data from the Brace Study of the Scoliosis Research Society. J Bone Joint Surg Am 1995; 77 (6): 815-22.

[25] Weiss HR, Weiss GM. Brace treatment during pubertal growth spurt in girls with idiopathic scoliosis (IS): A prospective trial comparing two different concepts. Pediatr Rehabil 2005; 8 (3): 199-206.

[26] Weinstein SL, Dolan LA, Wright JG, Dobbs MB. Effects of bracing in adolescents with idiopathic scoliosis. N Engl J Med 2013; 369 (16): 1512-21.

[27] Weiss HR, Goodall D. Rate of complications in scoliosis surgery-a systematic review of the Pub Med literature. Scoliosis 2008; 3: 9. 
[28] Weiss HR, Moramarco M, Moramarco K. Risks and long-term complications of adolescent idiopathic scoliosis surgery vs. non-surgical and natural history outcomes. Hard Tissue 2013;2 (3): 27.

[29] Scoliosis Research Society. 54th Annual Meeting, September 18-21, 2019, Montreal, Canada. Final Program. https://www.srs.org/UserFiles/file/am19-FPfull-sm2.pdf. Accessed April 9th. 2020.

[30] Yamada K, Miyamoto K, Hosoe H, Mizutani M Shimizu K. Scoliosis associated with Prader-Willi syndrome. Spine J. 2007; 7 (3), 345-348. PMID: 17482119.

[31] Dickson JH, Mirkovic S, Noble PC, Nalty T, Erwin WD. Results of operative treatment of idiopathic scoliosis in adults. J Bone Joint Surg Am. 1995, 77 (4), 513-23. PMID: 7713967.
[32] Trobisch PD, Ricart P, Bharucha N. [Clinical characteristics of patients who are lost to follow-up after surgical treatment for adolescent idiopathic scoliosis]. Z Orthop Unfall. 2012 Feb; 150 (1): 48-51.

[33] Weiss HR, Turnbull D. Brace Treatment for Children and Adolescents with Scoliosis [Online First], IntechOpen, DOI: 10.5772/intechopen.91234. Available from: https://www.intechopen.com/online-first/brace-treatment-for-c hildren-and-adolescents-with-scoliosis?fbclid=IwAR223NHkj aah5vYra6mK70x-kvAk7P1M_zA-iE4uWwirETgP3vglXqJc 1EM. (February 27th 2020).

[34] Mueller FJ, Gluch H. Cotrel-dubousset instrumentation for the correction of adolescent idiopathic scoliosis. Long-term results with an unexpected high revision rate. Scoliosis. 2012; 7 (1): 13 . 